\title{
Effects of stimulus associated with amobarbital administration on avoidance behavior.
}

\author{
DENNIS K. KAMANO \\ Galesburg State Research Hospital, Galesburg, Ilinois 61401
}

\begin{abstract}
The present study was concerned with the effect on avoidance responding of superimposing a stimulus which has previously been associated with amobarbital administration. Rats were given unsignaled shuttlebox avoidance training, then given separate Pavlovian conditioning (CS- amobarbital pairings) with avoidance training continuing on alternate days. The Pavlovian CS was then presented during two test sessions to determine its effect on the avoidance response. It was found that the Pavlovian CS through its association with amobarbital suppressed avoidance response rate when presented during nonsignaled avoidance behavior.
\end{abstract}

Previous studies have demonstrated that avoidance response rate can be altered by the presentation of a stimulus with excitatory or inhibitory property established independently by Pavlovian conditioning procedures. For example, the presentation of a stimulus which has previously been paired with shock (Pavlovian fear conditioning) during ongoing avoidance behavior enhances the response rate (e.g., Grossen \& Bolles, 1968; Kamano, 1970; Rescorla \& LoLordo, 1965). On the other hand, presenting a stimulus which has previously been paired with food suppresses avoidance responding (Bull \& Overmier, 1969; Grossen, Kostansek, \& Bolles, 1969). The present study is concerned with the effect on avoidance responding of superimposing a stimulus which has previously been paired with drug. That is, could a stimulus which has previously been associated with amobarbital administration exert any effect over avoidance behavior? Amobarbital is a CNS depressant with sedativeproperty (Kranz, Carr, \& $\mathrm{LaDu}, 1969$ ), and is said to attenuate fear-motivated behavior (e.g., Barry, Etheredge, \& Miller, 1965; Miller, 1961). Furthermore, it has been reported that amobarbital facilitates the extinction of (i.e., suppresses) unsignaled shuttlebox avoidance (Kamano, 1973), and, therefore, we should expect a stimulus associated with amobarbital administration to suppress avoidance behavior.

In the present study, rats were given training on an unsignaled avoidance schedule, then given separate Pavlovian conditioning (CS- amobarbital pairings), with avoidance training continuing on alternate days. The Pavlovian CS was then presented during two test sessions, and the hurdle-crossing rates in response to the superimposed Pavlovian CS were noted. This study, therefore, permitted the determination of the effect of superimposing a Pavlovian CS which has been paired with amobarbital on avoidance behavior.

\section{METHOD}

\section{Subjects}

Ss were 12 naive 52-60-day-old male Wistar albino rats from the colony maintained at the Galesburg State Research Hospital and were housed in individual cages throughout the experiment.

\section{Apparatus}

The apparatus was a modified Mowrer-Miller shuttlebox with a 10.16-cm-high hurdle and a drop gate that, when lowered, prevented hurdle crossing. A $10-\mathrm{W}$ light bulb mounted above each compartment served as the CS, and shock was delivered through a grid floor. Details of the apparatus and shock source are described elsewhere (Kamano, 1972).

\section{Procedure}

\section{Avoidance Training}

Ss received shuttlebox avoidance training on a free-operant avoidance schedule with a response-shock interval of $30 \mathrm{sec}$ and shock intensity of $0.8 \mathrm{~mA}$. Any hurdle-crossing response (i.e., avoidance response) postponed shock for $30 \mathrm{sec}$, and failure to respond within $30 \mathrm{sec}$ resulted in shock which remained on until $S$ made an escape response (i.e., crossed the hurdle into the opposite compartment). Each $\mathrm{S}$ had one 30 -min avoidance training session per day over 3 successive days.

\section{Pavlovian Conditioning}

Following 3 days of avoidance training, each $\mathrm{S}$ was confined to half of the shuttlebox and given five Pavlovian conditioning sessions, with avoidance training continuing on alternate days. The side of the shuttlebox used for the Pavlovian procedure alternated from day to day. Each Pavlovian session was preceded by a 30 -sec interval, after which the 10 -min light CS was presented, and an IP injection of $40 \mathrm{mg} / \mathrm{kg}$ amobarbital sodium or normal saline was administered $3 \mathrm{~min}$ after CS onset to the six drug and six placebo Ss, respectively. The procedure of removing, injecting, and replacing $S$ into the compartment required no more than $20 \mathrm{sec}$, and was modeled after that described by Cameron and Appel (1972). The S was removed from the apparatus $30 \mathrm{sec}$ after offset of the 10-min CS and returned to its home cage. Pavlovian conditioning and avoidance training were alternated for a total of 5 Pavlovian and 4 avoidance days.

\section{Test for CS Effect on Avoidance}

The alternating sequence was followed by a test session without drug that was identical to the avoidance training sessions except that (a) Ss performed the avoidance response without shock (i.e., under extinction conditions) and (b) the 30 -min test session began with a 10 -min interval, after which the CS was presented for $10 \mathrm{~min}$ followed by a 10 -min post-CS period. The 


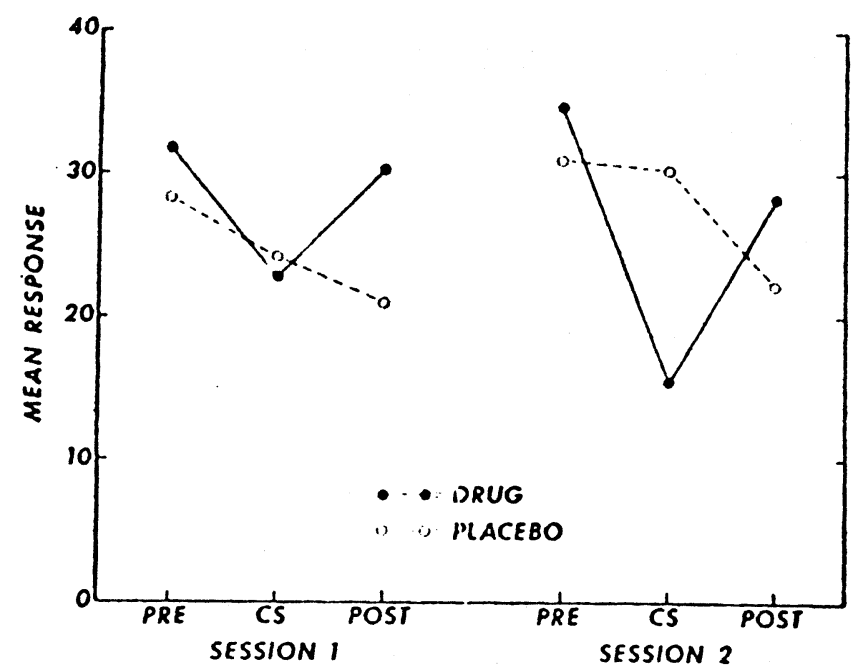

Fig. 1. Mean response for each group during $10-\mathrm{min}$ periods before, during, and following CS presentation over two test sessions.

number of avoidance responses in successive 10 -min periods preceding, during, and following CS presentation were recorded.

The test session was then followed in sequence by another avoidance training day, a Pavlovian conditioning day (with the same light-drug pairing as before), and a test day.

\section{RESULTS}

The mean number of responses for the drug and placebo groups during the 10 -min periods before, during, and following CS presentation over the two test sessions are presented in Fig. 1. It can be seen that the drug and placebo groups did not differ significantly on rateof responding during the pre-CS and CS periods, but differed significantly $(t=2.30, p<.05)$ during the post-CS period of the first session. In the second session, the drug and placebo groups did not differ significantly on rate of responding during the pre-CS and post-CS periods, but differed significantly $(\mathrm{t}=2.93, \mathrm{p}<.05)$

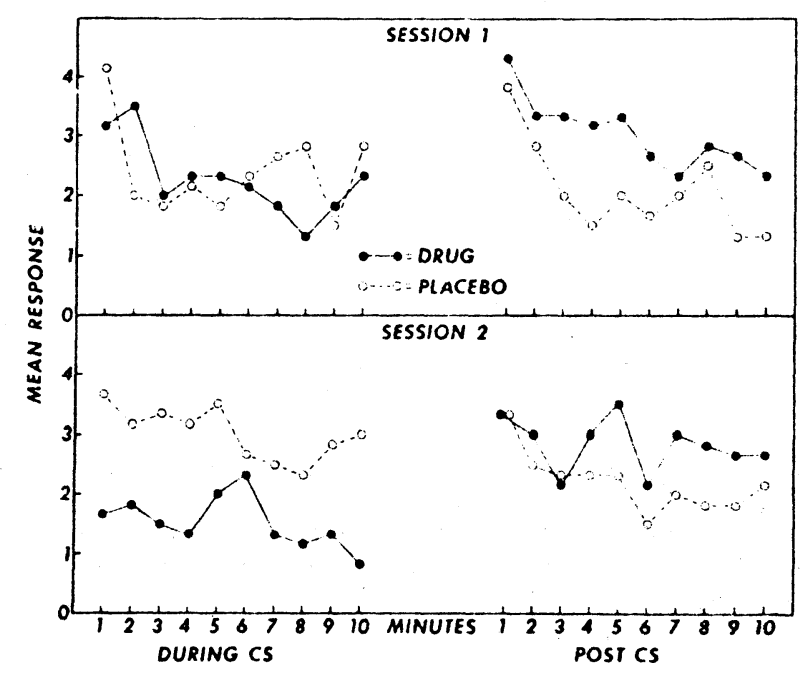

Fig. 2. Mean responses per minute during the $10-\mathrm{min} \mathrm{CS}$ and post-CS periods for each group over two test sessions. during the CS period. With the drug group, but not the nondrug group, the Ss returned from a lower rate of responding during the $\mathrm{CS}$ period to their higher pre-CS rates of responding during the period following CS offset in both sessions.

The responses to CS onset and its duration and to CS offset and duration are presented in Fig. 2. The rate of responding for the drug group as compared with the placebo group was consistently lower throughout the entire CS period in Session 2, but the rate of responding for the drug group was consistently higher than that of the placebo group during the post-CS period in both Sessions 1 and 2.

\section{DISCUSSION}

A stimulus which had been associated with amobarbital administration through Pavlovian conditioning revealed the capacity to decrease avoidance response rate when presented during nonsignaled avoidance responding. It is possible that the Pavlovian CS through its association with amobarbital, which has sedative and fear-reducing properties, exerted an inhibitory influence on avoidance performance by either evoking relaxational responses incompatible with the avoidance response or attenuating the fear that motivates avoidance responding.

With the drug group, but not with the nondrug group, the Ss returned from a suppressed level of responding during CS presentation to their higher pre-CS rates of responding following CS offset. The failure of the placebo group to reveal similar shifts in performance adds further support that the Pavlovian CS did, indeed, acquire a discriminative function. At any rate, this study has shown that environmental stimuli could become associated with drug administration, as reflected by the suppression of avoidance responding produced by the presentation of the Pavlovian CS previously paired with amobarbital.

\section{REFERENCES}

Barry, H., III, Etheredge, E. E., \& Miller, N. E. Counterconditioning and extinction of fear fail to transfer from amobarbital to nondrug state. Psychopharmacologia, $1965,8,150-156$.

Bull, J. A., III, \& Overmier, J. B. Incompatibility of appetitive and aversive conditioned motivation. Proceedings, 77 th Annual Convention, APA, 1969, 97-98.

Cameron, O. G., \& Appel, J. B. Conditioned suppression of bar-pressing behavior by stimuli associated with drugs. Journal of the Experimental Analysis of Behavior, 1972, 17, 127-137.

Grossen, N. E., \& Bolles, R. C. Effects of a classical conditioned 'fear signal' and 'safety signal' on nondiscriminated avoidance behavior. Psychonomic Science, 1968, 11, 321-322.

Grossen, N. E., Kostansek, D. J., \& Bolles, R. C. Effects of appetitive discriminative stimuli on avoidance behavior. Journal of Experimental Psychology, 1969, 81, 340-343.

Kamano, D. K. Types of Pavlovian conditioning procedures used in establishing CS+ and their effect upon avoidance behavior. Psychonomic Science, 1970, 18, 63-64. 
Kamano. D. K. Using drugs to modify the effect of response prevention on avoidance extinction. Behavior Research \& Therapy, 1972, 10, 367-370.

Kamano. D. K. Extinction of unsignaled shuttlebox avoidance and the effect exerted subsequently by a conditioned fear stimulus as a function of amobarbital. Psychopharmacologia, 1973, 28. 45-50.

Kranz, J. C., Jr., Carr, C. J., \& LaDu, B. N., Jr. The pharmacologic principles of medical practice. (7th ed.) Baltimore: Williams \& Wilkins, 1969.
Miller, N. E. Some recent studies of conflict behavior and drugs. American Psychologist, 1961, 16, 12-24.

Rescorla, R. A., \& LoLordo, V. M. Inhibition of avoidance behavior. Journal of Comparative \& Physiological Psychology, 1965. 59. 406-412.

(Received for publication May 11, 1973; revision received June 1,1973 ; accepted June 18, 1973.) 